\title{
Clemente Romano, sembrador de fraternidad en la Carta a los Corintios
}

\author{
MARÍA INÉS CASTELLARO \\ Centro de Estudios Filosóficos y Teológicos (Córdoba-Argentina) \\ maria_inescastellaro@hotmail.com
}

\begin{abstract}
Resumen
Clemente Romano es el hombre de la reconciliación, que busca sembrar en aquellos que lo escuchan una semilla de fraternidad. Él sabe que en el corazón del hombre anidan las malas pasiones, los sentimientos de envidia y de división pero también sabe que quien vive en el amor, quien pone su mirada en el Dios que es Amor se transforma, se convierte. El único camino es Jesucristo y por eso continuamente invita, a través de sus palabras, a fijar la mirada en Él. Misericordia, humildad, sencillez, corrección fraterna, hospitalidad son palabras que a lo largo de la carta a los Corintios se entrelazan tejiendo la trama del amor al hermano y del amor a Dios. ¿Qué nos enseña esta carta escrita muchos siglos atrás y que parece tan actual? Es un desafío para el hombre peregrino de hoy que siente por un lado, la sed de espiritualidad, y por otro, el ansia del poder, del tener, del placer, a contemplar a un Dios que lo ama y a buscar sólo el bien del hermano, caminando junto a él con sencillez y humildad.
\end{abstract}

Palabras claves: fraternidad, reconciliación, humildad, iglesia peregrina, conversión.

\section{Clement of Rome, planter fraternity in the Letter to the Corinthians}

\begin{abstract}
Clement of Rome is the man of reconciliation, which seeks to sow those who hear a seed of fraternity. He knows the heart of man nest evil passions, feelings of envy and division but also knows that whoever lives in love, who sets her sights on the God who is Love becomes becomes. The only way is Jesus Christ and so continuously invited, through his words, to stare at bim. Mercy, humility, simplicity, fraternal correction, hospitality are words along the Corinthians intertwine weaving Brother love story and love of God. What can we learn this letter written many centuries ago and it seems so today? It is a challenge for pilgrims today man who feels the one hand, the thirst for spirituality, and secondly, the lust of power, possessions, pleasure, to contemplate a God who loves him and seek only good brother walking beside bim with simplicity and bumility.
\end{abstract}

Key words: brotherbood, reconciliation, bumility, pilgrim church, conversion.

Religiosa perteneciente a la Congregación de las Hermanas de la Virgen Niña. Licenciada en Teología Pastoral-Espiritual en la Facultad Teológica de la Italia Septentrional con sede en Milán (Italia). Diplomada en Espiritualidad en el Centro de Estudios de Espiritualidad, dependiente de la Facultad Teológica de la Italia Septentrional, Milán (Italia). Docente en diversas cátedras en el CEFyT e ITeC de la ciudad de Córdoba (Argentina). Tutora de los cursos de teología a distancia.

Recibido: 30/Septiembre/2015 - Aceptado: 10/Noviembre/2015 


\section{Introducción}

Clemente Romano es un hombre de Dios. No sabemos mucho de sus orígenes pero sí podemos conocer el amor a Dios y la sed de fraternidad que se pone de manifiesto en el servicio de la autoridad a la Iglesia de Dios, concretamente a la Iglesia que peregrina en Corintios. No se presentará una exégesis de la carta escrita a fines del siglo I sino más bien dejar que ella nos hable de la identidad y de la misión, de las características y de las dificultades de esta porción de pueblo de Dios.

Muchos temas se entrecruzan en la carta pero el hilo principal es el amor a Dios, el Dios creador, que modela al hombre a su imagen y semejanza para introducirlo en su propio mundo, en la vida de Dios. La misericordia y dulzura de Dios se manifiestan en la cercanía a las creaturas y derrama sus dones y beneficios. Dios cuida, protege al hombre y no abandona al que espera en Él y por eso ofrece y sigue ofreciendo en Cristo la ocasión de conversión y lo corrige como Padre de misericordia, buscando que viva en fraternidad. Y nos podemos preguntar, ¿por qué es tan importante la fraternidad? ¿Cómo podemos relacionar a Clemente, sembrador de fraternidad con el tema de la misericordia, propuesto por el papa Francisco para este año dedicado de un modo especial a descubrir a Dios como Padre misericordioso? ¿Cómo desde esa experiencia de 'entrañas de misericordia' podemos ayudar a crecer a la comunidad donde estamos insertos?

De esta manera el artículo propone presentar a Clemente como el hombre fraterno que invita concretamente a la comunidad de Corintios a la conversión, a crear lazos de comunión superando las tentaciones que brotan del corazón del hombre cuando está lleno de sí y no tiene espacio para el Amor, a ser una comunidad donde se vive el amor misericordioso de un Dios Trinidad.

En el primer apartado presentaremos brevemente a Clemente, el papa de fines del siglo I; en el segundo la carta que escribe a la Iglesia de Dios peregrina en Corintios; en el tercer acápite nos introducirnos en esta Iglesia conociendo su identidad y misión, sus dones, sus riquezas y también sus dificultades y finalmente haremos referencia al camino que Clemente propone a recorrer para hacer fructificar los dones y superar las obstáculos en la comunidad, y así crecer en fraternidad y misericordia, ya que sólo reconociendo la misericordia se restablece la fraternidad.

\section{Los orígenes de Clemente Romano}

De Clemente no se sabe con certeza cuando nació, sólo tenemos noticias del lugar de su nacimiento que fue en Roma. Fue elegido Papa y 
murió en el año 99 o 100, pocos años después de la composición de la carta a los Corintios, en Ponto (Asia Menor) (Fernández, 2002). Fue un cristiano insigne de finales del siglo I, uno de los llamados Padres Apostólicos en cuanto que transmitió el eco vivo de la predicación de los apóstoles de Jesús de Nazaret (Ruiz Bueno, 2002).

Es el tercer sucesor de Pedro después de Lino (hasta el año 80) y Anacleto, también llamado Cleto (80-92). Ireneo de Lyon afirma que "después de ellos, en tercer lugar desde los apóstoles, accedió al episcopado Clemente, que no solo vio a los propios apóstoles sino que con ellos conversó y pudo valorar detenidamente tanto la predicación como la tradición apostólica" (Ireneo, 2000: 124).Clemente fue el cuarto de los Papas. Ireneo considera a este vicario de Cristo como un eslabón importante en la cadena de la continuidad, por su conocimiento y por su fidelidad a la doctrina recibida de los apóstoles (Loarte, 1998).

Domiciano era el emperador (81-96) en el tiempo de su pontificado por lo que resulta que Clemente inició su pontificado en el año $92 \mathrm{y}$ cuando acabó su vida estaba Trajano (98-117) al frente del imperio.

Clemente es conocido como uno de los padres pre-nicenos, anteriores al Concilio de Nicea (325) junto a Policarpo de Esmirna, Papías de Hierápolis, Hermas, entre otros.

¿Qué mensaje nos dejan estos padres apostólicos pre-nicenos y en especial Clemente? Lo primero que podemos expresar es que ellos nos dejan su particular interés por la Iglesia, toda su atención está centrada en la vida interior de la Iglesia y no tanto en el mundo externo. La Iglesia era la nueva realidad que había surgido y para el mundo antiguo era algo insólito, desconocido. Destaca, y bien lo pone de manifiesto Clemente, la unidad de la Iglesia. Unidad que está fundada en el amor recíproco y en el amor hacia los otros.

Los padres apostólicos y en este caso Clemente se comunican a través de cartas porque es uno de los medios de comunicación entre los hombres y también para dar noticias. Las cartas generalmente tienen un enfoque catequético, como doctrina dirigida a reforzar los puntos esenciales del mensaje cristiano.

Clemente es un verdadero testimonio de la fe de la Iglesia, no es un teólogo sino más bien un intérprete de la fe y lo podemos constatar en este ejemplo: no trata el problema de la relación entre las tres personas de la Trinidad, pero es testimonio de que en su Iglesia se confesaba la Trinidad y se contemplaba en su misterio.

Otra nota que podemos subrayar es que las comunidades (iglesias locales) tenían una vida organizada, con ministros que servían pero también tenían conciencia de ser parte del cuerpo de la Iglesia, eran sus miembros; cada comunidad se sentía unida al cuerpo de la Iglesia. 
La espiritualidad de la Iglesia aparece en el escrito fuertemente inspirada en la Sagrada Escritura. El cristiano debe tener una vivencia no solo interior sino que verdaderamente debe ser cristiano, sembrador de fraternidad.

Fuera de estos datos nada se sabe de la vida anterior de Clemente, y de su mismo episcopado sólo quedó la carta a los cristianos de Corinto. No es posible probar que Clemente de Roma sea el mismo que san $\mathrm{Pa}$ blo alaba en su carta a los Filipenses $(4,3)$ y tampoco pueden aducirse pruebas de su martirio (Contreras \& Peña, 1990).

\section{La carta a la Iglesia de Corinto}

Es uno de los más importantes documentos del período que sigue inmediatamente a la época de los apóstoles, la primera pieza de la literatura cristiana, fuera del Nuevo Testamento, de la que constan históricamente el nombre, la situación y la época del autor (Quasten, 1968).

Es el único escrito que tenemos de Clemente aunque sí se le atribuyeron otros escritos por su autoridad y prestigio. Eusebio de Cesarea la presenta con estas expresiones "Nos ha llegado una carta de Clemente reconocida como auténtica, grande y admirable. Fue escrita por él, de parte de la Iglesia de Roma a la Iglesia de Corinto. Sabemos que desde hace mucho tiempo y todavía hoy es leída públicamente durante la asamblea de los fieles" (Eusebio de Cesarea 2000: 303).

En su carta, Clemente, no se menciona a sí mismo por su nombre. La que envía la carta es la Iglesia de Dios que vive en Roma (Clemente, 1994). Cuando se refiere a sí mismo el autor usa el pronombre plural nosotros. Más allá de esto, la obra fue escrita por una sola persona y esto lo pone de relieve la unidad de estilo y de pensamiento. A lo que parece, Clemente tuvo en cuenta que su mensaje sería considerado público más que privado, previó que se leería a una comunidad cristiana reunida en el culto divino. Por eso la carta está muy elaborada y con varias figuras retóricas. Clemente tuvo el propósito de dar a este documento una importancia que trascendiera la ocasión inmediata que la motivó (Quasten, 1968).

En cuanto al origen del autor, parece ser judío. Las frecuentes citas del Antiguo Testamento y las relativamente pocas del Nuevo Testamento corroboran esta conjetura (Quasten, 1968).

El problema que se plantea es la datación de esta carta. En los primeros párrafos de la misma, el autor se excusa por la tardanza con que responde a los asuntos que atañen a esa comunidad y esa tardanza la justifica a causa de las repentinas y sucesivas desgracias y contratiempos que nos han sobrevenido (Clemente, 1994: I, 1). Estas palabras están a 
indicar, según Eusebio (2000), que la Iglesia de Roma acababa de salir de una difícil situación que podría ser la persecución de Domiciano. Otros autores lo relacionan con la persecución de Nerón pero llevaría a no encontrar explicación a algunos elementos de la carta como por ejemplo: el lapso de tiempo entre la muerte de los apóstoles y el momento de redacción de la carta; lapso de tiempo en que los episkopoi elegidos por los apóstoles fueron sucedidos por otros (Clemente, 1994: XLII,4; XLIV, 23); a la Iglesia de Corinto se la llama antigua, que se remonta a los orígenes (Clemente, 1994: XLVII, 6); los mensajeros que llevan la carta son individuos que tuvieron una buena conducta en la comunidad romana (Clemente, 1994: LXIII,3). Esto lleva a pensar que la carta fue escrita entre el 95 y el 98, es decir casi al finalizar su papado. Otros autores utilizan varios argumentos de escasa consideración para no estar de acuerdo con dicha fecha (Ayán, 1994).

En cuanto al motivo de la carta fue la revuelta chocante e impropia de los elegidos de Dios, infame y sacrílega (Clemente, 1994: I, 1) que tuvo como centro la comunidad de Corinto y por la que unos individuos arrogantes y audaces (Clemente, 1994: I,1) depusieron de sus cargos a los presbíteros que estaban al frente de la comunidad (Clemente, 1994: XLIV, 6). Es claro que la carta no presenta otro problema que el de la revuelta. No es un problema doctrinal, sino una revuelta. No se sabe cómo llegó a Roma la noticia de la misma, tal vez algunos cristianos romanos residentes en Corinto, testigos de las discordias y disensiones informaron a Roma de la situación. Clemente lo que desea es restablecer las diferencias y reparar el escándalo dado a los paganos. Es un llamado a la paz y quiere inducir a los cristianos de Corinto a la penitencia y al arrepentimiento de aquellos que se habían rebelado contra la legítima autoridad que se fundaba sobre la tradición apostólica (Loarte, 1998).

Esta comunidad a la que san Pablo había dedicado grandes cuidados y reprehensiones paternales con motivo de otros desórdenes, vuelve a repetir ciertas discordias. El tono de la carta combina la dulzura y la firmeza de un padre, pero Clemente escribe teniendo presente su responsabilidad en la Iglesia y hasta se disculpa por no haber intervenido con prontitud. Es un testimonio sobre la primacía de Roma como cabeza de la Iglesia universal, primer ejercicio del primado de Roma después de la muerte de Pedro.

Ireneo alude a la triste situación: "Bajo el gobierno de Clemente se produjo entre los hermanos de Corinto una divergencia de opiniones no pequeña; la Iglesia de Roma envió a los Corintios una carta importantísima para reconciliarlos en la paz, renovar su fe y anunciarles la tradición que ella había recibido recientemente de los Apóstoles" (Ireneo 2000: 124).

VERITAS, No 34 (Marzo 2016) 
La carta se compone de dos partes. Brunner, en la introducción que realiza a la obra de Clemente (Clemente, 1994: 25-28) ofreció la estructuración más adecuada distinguiendo además de una introducción y una conclusión, dos secciones fundamentales compuestas cada una por cinco partes relacionadas entre sí:

Primera sección

1. Mirada retrospectiva en que se bosqueja el orden que existía en la comunidad de Corinto (I,2 - II,8)

2. Censura del desorden actual (III,1- VI,4)

3. Exhortación para recobrar el orden mediante la conversión, la obediencia y la humildad (VII,1- XIX,1)

4. El fin: la paz y la concordia que restablezca el orden (XIX,2 XXII,9)

5. Motivaciones para emprender el camino (XXIII,1 - XXXIX,9)

Segunda sección

1. Mirada retrospectiva en que se bosqueja el orden que existía en la comunidad de Corinto (XLII, 1-XLIV, 2)

2. Censura del desorden actual (XLIV, 3 - XLVII, 7)

3. Se propone recobrar el orden como hermanos (XLVIII, 1 - L, 7)

4. Exhortación para alcanzar el orden de manera que los culpables confiesen su culpa y emprendan el destierro (LI, 1 - LV, 6)

5. Motivaciones para el camino propuesto (LVI, 1-LXI, 3)

Conclusión (LXII, 1-LXV,2)

La introducción llama la atención sobre el estado floreciente de la comunidad cristiana de Corinto antes de las disputas, la armonía que existía entre sus miembros y el celo por el bien. El capítulo tercero, por contraste, señala la dificultad en la comunidad.

La primera parte tiene más bien carácter general, desaprueba la discordia y la envidia y cita varios ejemplos de estos vicios en textos del Antiguo Testamento así como de la época de los cristianos (Clemente, 1994: IV-VI). Él exhorta a la penitencia, a la hospitalidad, a la piedad, a la humildad y corrobora su argumentación con varias citas y ejemplos. El autor luego hace referencia a la bondad de Dios, a la armonía en la creación, en la omnipotencia de Dios, la resurrección y el juicio. La humildad, templanza, fe y buenas obras llevan a la recompensa, llevan a Cristo.

La segunda parte se ocupa de las disputas entre los cristianos de Corinto. Dios, el Creador del orden de la naturaleza exige de sus criaturas orden y obediencia. Para probar la necesidad de disciplina y obediencia trae el ejemplo del ejército romano y pone de manifiesto la existencia de la jerarquía en el Antiguo Testamento y afirma que por esta misma razón Cristo llamó a los apóstoles y éstos a su vez nombraron obispos y diáco- 
nos. El amor debería ocupar el puesto de la envidia, de la discordia y la caridad debería apresurarse a perdonar. A los que promueven la discordia los exhorta a la penitencia y a la obediencia.

En la conclusión se resume la exhortación y se expresa el deseo de que los portadores de la carta vuelvan pronto a Roma con la buena noticia de la paz que nuevamente reina en Corinto (Quasten, 1968).

Esta carta no es un tratado teológico y no podemos buscar en ella una exposición detallada del pensamiento teológico que se estaba desarrollando a fines del siglo I en Roma. Clemente busca dar una salida a las discordias y problemas surgidos en la comunidad de Corinto pero a lo largo del escrito deja un testimonio de la teología que estaba naciendo en la comunidad de Roma.

Dios Padre, Cristo, el Espíritu, la Iglesia, el ministerio, la sucesión apostólica, el primado de la Iglesia de Roma, la liturgia entre otros, son argumentos que recorren esta carta donde la Sagrada Escritura ocupa un lugar importante poniendo en evidencia la veneración de Clemente por ella. Citas del Antiguo Testamento textuales y a veces largos pasajes se entrelazan con citas del Nuevo Testamento, aunque son menos numerosas.

Ahora quisiéramos detenernos y profundizar uno de esos aspectos: la Iglesia. Nos preguntamos ¿cómo entendía la Iglesia? ¿Qué aspectos remarca en ella? ¿Dónde coloca el acento? ¿Quiénes forman parte de la Iglesia? ¿Cómo son las relaciones? ¿Cuál es su identidad y misión? ¿Podemos decir que es una Iglesia que vivió la misericordia de Dios y la expresó en las relaciones intra y extra eclesiales?

\section{La Iglesia en la carta a los Corintios}

El término Iglesia aparece pocas veces en la carta de Clemente (Clemente, 1994: Introd.; XLIV, 3; XLVII, 6). Clemente conocía muy bien los Setenta y con el término Iglesia habían traducido qehal Yabveh, expresión con la que se designaba a Israel en cuanto asamblea de Dios. Clemente ve prefigurado en el pueblo elegido del Antiguo Testamento la estructura, la organización, los peligros y las soluciones de la Iglesia (Clemente, 1994: XLII, XLI, XLIII). De aquí se puede deducir que Clemente consideraba a la Iglesia como el nuevo Israel, el nuevo pueblo elegido en el que Dios depositó sus promesas. En la oración final de la carta escribe: "Que conozcan todos los pueblos que Tú eres el único Dios, que Jesucristo es tu siervo y que nosotros somos tu pueblo, ovejas de tu rebaño" (Clemente, 1994: LIX, 4) haciendo alusión al texto de los Salmos 78,13 y 99,3. 
La Introducción de la carta tiene numerosas insinuaciones eclesiológicas: "La Iglesia de Dios que peregrina en Roma, a la Iglesia de Dios que peregrina en Corinto, a los que han sido llamados y santificados en la voluntad de Dios por medio de nuestro Señor Jesucristo" (Clemente, 1994: I,1). En estas pocas palabras encontramos una gran riqueza: en primer lugar la referencia a la Iglesia de Dios. Dios como referencia, Dios el sujeto, el que convoca, llama, es la Iglesia de su pertenencia. Sólo en la introducción a la carta hace esta referencia. Es importante remarcar este sentido de pertenencia a Dios, sentirse uno con Él.

Otra expresión que llama la atención es peregrina. El término utilizado por Clemente significa residir en un lugar como forastero, permanecer temporalmente, estar de paso, peregrinar y se opone a habitar de manera estable, tener residencia fija. El tema del cristiano como peregrino y forastero en esta tierra aparece en la Sagrada Escritura y en los escritos de la Iglesia primitiva con mucha fuerza ( $\mathrm{Hb} 11,13 ; 1 \mathrm{Pe} \mathrm{1,} \mathrm{17;}$ 2,11). El cristiano camina constantemente en busca de la ciudad futura, por eso no tiene una demora fija, una residencia estable. Está de paso, camina a paso ligero, desprendido, con pocas cosas, con lo necesario para anunciar el Reino.

Es la Iglesia de Dios que peregrina en Roma a la Iglesia de Dios, que peregrina en Corinto. En estas palabras aparece el carácter universal de la Iglesia, su concreción en las comunidades locales. El centro es Roma, y parece que esa Iglesia de Roma habla a la de Corinto como un superior a su súbdito, parecería que en el lenguaje manifiesta una cierta autoridad, expresada también en la disculpa que se pide por no actuar con prontitud (Clemente, 1994: I, 1), evidencia que esta Iglesia, cuyo responsable es Clemente, se cree en autoridad para llamarla al orden, para corregirla. Algunos autores ven que es un simple testimonio de solidaridad cristiana. Pero es claro que esta carta no nace simplemente de sentimientos solidarios, porque Clemente no se limita a invitar o a exhortar sino que da órdenes y exige obediencia (Clemente, 1994: LVII, 1; LXII,1-2) y más aún, la desobediencia supone un pecado y un peligro no pequeño (Clemente, 1994: LIX,1). Es importante notar que no solo se prestó obediencia a la intervención de Clemente en los asuntos de la Iglesia de Corinto, no fue vista como una injerencia injustificada, sino que se prestó veneración a su intervención, así en esta carta aparece una autoridad profética, una primacía religiosa que encuentra la mejor explicación en el primado romano.

La Iglesia es la asamblea de los llamados; está fundada sobre una llamada que tiene su iniciativa en Dios: "nos hizo porción de sus elegidos" (Clemente, 1994: XXIX, 1). Esta llamada no se puede separar de Cristo porque Él es el primer elegido (Clemente, 1994: LXIV) y los 
miembros de la Iglesia fueron llamados por medio de Cristo (Clemente, 1994: I, 1; L, 7; LIX,3) y en Cristo (Clemente, 1994: XXXII,4; XLVI,7).

La disensión en la comunidad eclesial impulsa a Clemente a poner un especial acento en la concordia y unidad que debe caracterizar a la Iglesia presentándola a través de imágenes como la del cuerpo (Clemente, 1994: XXXVIII; XLVI, 7) o rebaño de Cristo (Clemente, 1994: XLIV, 3; LIV,2) e incluso recurre a la semejanza de la unidad del ejército (Clemente, 1994: XXXVII,2-3; Ayán,1994).

Podemos afirmar que el motivo inmediato de la carta le permite a Clemente explicar ampliamente la identidad y la misión de la Iglesia.

\subsection{Identidad y misión de la Iglesia de Corinto}

A través de la lectura de esta carta podemos recabar la identidad de esta comunidad, sus características, su misión, el ser de la Iglesia de Corinto. Ya lo hemos visto en el apartado anterior el sentido de pertenencia a Dios y su ser peregrina, su llamado y su santidad en Dios. Haciendo un recorrido a través de la carta remarcamos algunas expresiones significativas: una comunidad que se caracteriza por una fe virtuosa en todo y firme, reflejada en la experiencia de vida de los miembros y no sólo en el conocimiento de las verdades de la fe; una sensata y equilibrada piedad en Cristo, la experiencia de Cristo como "Quien constituye, inspira, sostiene a la Iglesia, es el que obra y provee a los fieles, los auxilios necesarios" (Clemente, 1994: II,1), es el mediador entre Dios y los hombres (Clemente, 1994: XLII,1; L,7). No sólo se evidencia en esta comunidad la dimensión vertical, sino la dimensión de la fraternidad, en la expresión generosa costumbre de vuestra hospitalidad. Este tema reaparece en varios párrafos (Clemente, 1994: X, 7; XI,1; XII,1; XXXV,5). La apertura de corazón, el desinterés y la generosidad en recibir a los hermanos de otras Iglesias y esto unido a la expresión todo lo hacíais sin acepción de personas, la no discriminación es un rasgo importante.

Se subraya asimismo la ciencia eminente y sólida, la obediencia a vuestros jefes, el caminar en las leyes de Dios, el honor a vuestros ancianos y podemos seguir con la relación con los jóvenes a los que les legaba un pensar equilibrado y venerable; a las mujeres les exigíais cumplir todo con conciencia irreprochable, venerable y pura, amando a los maridos como conviene, hasta les enseñaba a realizar con dignidad las tareas domésticas, según el principio de la obediencia, de forma que eran prudente en todo (Clemente, 1994: I,1). Una comunidad que estaba atenta a todos: jóvenes, mujeres, ancianos, forasteros y una comunidad caracterizada por la obediencia, una comunidad que no hacía exclusión de personas, una comunidad inclusiva.

VERITAS, No 34 (Marzo 2016) 
Otra característica son los sentimientos de humildad, humildad opuesta al jactarse; la obediencia que se oponía al imponer y sentimientos de alegría más en el dar que en el recibir. Una comunidad que se alegraba y confiaba en los auxilios de Cristo y esto se ponía de manifiesto en el abrazar sus palabras y los sufrimientos y el fruto de esas actitudes era la paz profunda y radiante y un deseo continuo por las buenas obras y la efusión del Espíritu Santo.

Una comunidad orante (Clemente, 1994: XXIX, 1) porque llena de santa voluntad, con buen deseo, con piadosa confianza, elevaban sus manos a Dios todopoderoso. Una oración de súplica en la que imploraban a Dios todopoderoso la indulgencia si hubiesen pecado.

Una comunidad que día y noche luchaban a favor de todos los hermanos para que por medio de la piedad y la comunión de sentimientos se salvase el número de los elegidos. La importancia de la salvación del hermano, de la liberación, de la sanación interior de quien está a su lado.

Una comunidad caracterizada por la pureza, la integridad y el no tener resentimientos hacia los demás hasta considerar toda pelea, toda revuelta, todo cisma como algo a detestar, y llegaban a llorar por los pecados del prójimo y hasta las necesidades del otro eran sentidas como propias; siempre dispuestos a hacer el bien, a tender una mano al hermano más necesitado y todo lo hacían según las órdenes y decretos del Señor que estaban escritas en sus corazones (Clemente, 1994: II;1-8).

Podemos seguir recorriendo la carta y remarcando otras características: el orden en el cumplimiento de las ofrendas y ministerios porque los que hacen sus ofrendas en los tiempos y ocasiones definidos son aceptos y bienaventurados por la obediencia a la ley (Clemente, 1994: L, 1.4).

Se remarca no sólo la identidad sino la misión de esta Iglesia fundada en el envío de los apóstoles por parte de Jesucristo, enviado de Dios (Clemente, 1994: XLII, 1ss): el envío de obispos y diáconos (una comunidad organizada ministerialmente, Clemente, 1994: IX, 5) y se habla de los laicos con una misión determinada (Clemente, 1994: XLII,1.5) pero con el único fin de agradar a Dios.

Además presenta la constitución de la Iglesia: al sumo sacerdote le estaban encomendadas las funciones litúrgicas propias; los sacerdotes ordinarios tenían asignado su lugar propio; los levitas tenían encomendados sus propios servicios mientras que el laico estaba sometido a los preceptos laicos (Clemente, 1994: XL,1-5). Llama la atención que por primera vez en esta carta de fines del siglo I aparece el término laikós que significa "miembro del laos", es decir, del pueblo de Dios.

Clemente en referencia a la liturgia del antiguo Israel manifiesta su ideal de Iglesia, congregada por "un solo Espíritu de gracia derramado sobre nosotros", que sopla en los diversos miembros del Cuerpo de Cris- 
to, en el que todos, unidos sin ninguna separación, son "miembros los unos de los otros" (Clemente, 1994: XLVI, 6-7).

La distinción entre los laicos y la jerarquía no significa una contraposición sino la conexión de un cuerpo, con distintas funciones. No hay en la Iglesia confusión sino orden, armonía donde cada uno ejerce su ministerio según la vocación recibida.

En cuanto a los jefes de las comunidades, Clemente explica la doctrina de la sucesión apostólica y las normas que la regulan derivan del mismo Dios. Así como el Padre envió al Hijo, el Hijo envió a los apóstoles y éstos luego enviaron a los primeros jefes de las comunidades y establecieron que a ellos les sucedieran otros hombres dignos y por eso todo procede "ordenadamente por voluntad de Dios" (Clemente, 1994: XLII). Clemente remarca que la Iglesia tiene una estructura sacramental y no política. La acción de Dios que sale al encuentro del hombre en la liturgia, precede las decisiones e ideas.

La Iglesia es don de Dios y no creación del hombre y esa estructura sacramental garantiza la precedencia del don de Dios que todo hombre necesita y no solo un ordenamiento común.

\subsection{Dificultades en la Iglesia de Corinto}

Pero, ¿cuál es el motivo de los abusos, de las discusiones, de la revuelta? El motivo de los abusos, de las discusiones y peleas hay que buscarlo en el venir a menos de la caridad y de las virtudes cristianas que son indispensables para la unidad de la Iglesia.

Ese venir a menos de las virtudes está expresado en la envidia, que encierra todos los malos sentimientos y pasiones, la malevolencia, disputa y revuelta, persecución y desorden, guerra y cautividad. Esto llevó a las disputas entre los sin honor y los honrados, los sin gloria y los ilustres, los insensatos y los prudentes, los jóvenes y ancianos. Eso trajo como consecuencia la falta de justicia, de paz ya que el temor de Dios había quedado a un lado, la fe fue apagándose y la ley del Señor fue olvidada porque cada uno buscaba su propio bien y no el del hermano, cada uno se dejaba llevar por sus propias pasiones e intereses (Clemente, 1994: III,1-4).

La envidia, la emulación es la causa ya en el Antiguo Testamento del fratricidio entre Caín y Abel y de tantos otros ejemplos de personajes que huyeron, fueron perseguidos, se rebelaron (Clemente, 1994: IV,8-13) y hasta en el Nuevo Testamento podemos encontrar otros tantos ejemplos (Clemente, 1994: V,1-VI,4).

Clemente en su carta presenta esta situación de separación, de división y de rebelación contra la Iglesia misma, hasta el punto de llegar a 
que uno es miembro del otro, (Clemente, 1994: XLVI, 7) y hasta esa división llevó a que varios se extraviaran, fueran por caminos equivocados, a otros los llevó al desaliento, otros a la duda pero a todos a la tristeza (Clemente, 1994: XLVI, 9).

El motivo principal es que algunas personas se han rebelado contra los presbíteros (Clemente, 1994: XLVIII, 6) y la causa es la envidia. Se han dejado llevar por el mal espíritu de la envidia.

\section{Un programa de vida}

¿Qué hacer ante esta situación de división, de envidia, de discordia, de rebelión? Clemente muy claramente hace una invitación a la humildad $y$ al amor fraterno, que son las dos virtudes que constituyen verdaderamente el ser en la Iglesia: "Seamos una porción santa", exhorta, "practiquemos todo lo que exige la santidad” (Clemente, 1994: XXX, 1).

Una fuerte invitación es a abandonar las preocupaciones vanas y necias y recurrir a la gloriosa y venerable regla de la tradición, a fijar los ojos en la sangre de Cristo y el valor de la sangre de Cristo ofreció la ocasión de conversión (Clemente, 1994: VII, 2-5). Conversión es la palabra clave en este camino.

Dejar de lado preocupaciones inútiles, contiendas y la envidia que conduce a la muerte y para eso es necesario suplicar el don de la misericordia (Clemente, 1994: IX, 1).

Son significativos los numerosos ejemplos de personajes del Antiguo y Nuevo Testamento que desde una actitud de obediencia (Clemente, 1994: X,1-6), de piedad, de hospitalidad (Clemente, 1994: X,7-XI,1-XII13), de fe, humildad, de desprendimiento de la jactancia, de la vanidad, de la insensatez, de la ira (Clemente, 1994: XIII,1-2) se fortalecieron para caminar en la obediencia, con sentimientos de humildad.

Conducirse en la misericordia y la dulzura (Clemente, 1994: XIV, 14), unirse a los que construyen la paz con piedad y no los que desean la paz con la hipocresía (Clemente, 1994: XV, 1) y el más claro ejemplo está en Jesucristo que no vino con el alboroto de la jactancia y de la soberbia sino con sentimientos de humildad (Clemente, 1994: XVI, 1-2). La invitación es a ser imitadores de Cristo como lo fueron tantos hombres a lo largo de la historia del pueblo de Dios (Clemente, 1994: XVII, 1-5. XVIII, 1-2), imitadores en la humildad y obediencia.

Por otro lado la invitación es a reconocer los pecados y a pedir que los mismos sean perdonados (Clemente, 1994: LII, 1-2), confesar las faltas cometidas (Clemente, 1994: LIII, 1) y a eso solo se puede llegar cuando se experimenta el amor de Dios, su misericordia (Clemente, 1994: LIII,5). 
Buscar la voluntad de Dios, reverenciar a Jesucristo, respetar a los jefes, honrar a los ancianos, educar a los jóvenes en el temor de Dios, encaminar a las mujeres al bien, ser puros, manifestar el propósito de la mansedumbre, evidenciar la discreción de la lengua por medio del silencio, no seguir las inclinaciones que alejen del amor, vivir en la humildad, escudriñar los pensamientos e intenciones, es de verdad un proyecto de vida para vivir en la fraternidad (Clemente, 1994: XXI,1-9), en el amor al hermano y a Dios porque quien ama a su hermano, ama a Dios. Todo este proyecto es consolidado en la fe (Clemente, 1994: XXII, 1) que nos hace mirar en la esperanza hacia los bienes futuros (Clemente, 1994: XXIII. XXIV).

Huir de la calumnia, de la unión infame e impura, de las embriagueces, de las revueltas, de los deseos repugnantes, del adulterio, de la soberbia y buscar solo la santidad manifestada en la concordia, en los sentimientos de humildad, en el dominio de sí, alejados de la murmuración, de la calumnia, siendo justos con obras y no con palabras (Clemente, 1994: XXX,1-3).

La osadía, la arrogancia y el atrevimiento son característicos de aquellos que están alejados de Dios mientras que la moderación, la humildad y la mansedumbre caracterizan a los bendecidos por Dios (Clemente, 1994: XXX, 8).

La sencillez lleva a conocer la grandeza de los dones que Dios concede (Clemente, 1994: XXXII, 1). Esforzarse por obrar bien, con perseverancia, con celo y buena voluntad y abandonarse al amor (Clemente, 1994: XXXIII). Creer en Él, obedecer su voluntad, reunirse en concordia, en comunión de sentimientos, invocar al Altísimo para que nos haga partícipes de sus promesas (Clemente, 1994: XXXIV). Apoyar nuestro pensamiento en Dios, buscar lo que es grato y acepto, cumplir su voluntad, seguir el camino de la verdad, quitar toda injusticia y maldad: ambición, discordias, malas costumbres, engaños, murmuraciones, calumnias, impiedad, soberbia, jactancia, vanagloria, falta de hospitalidad (Clemente, 1994: XXXV,5). Es un verdadero programa de vida para quien busca seguir a Cristo en una comunidad fraterna.

El camino es Jesucristo y por eso la invitación a fijar la mirada en Él (Clemente, 1994: XXXVI), a conservar nuestro cuerpo en El, sometiéndose cada uno a su prójimo, cuidando del más débil y respetando al más fuerte; el rico proveyendo al pobre y éste agradeciendo a Dios por haber recibido algo; el sabio muestre su sabiduría con obras y el humilde debe dejarse alabar por otro (Clemente, 1994: XXXVIII). Reconocer la misericordia restablece el amor fraterno (Clemente, 1994: XLVIII,1), dejarse corregir por el hermano (Clemente, 1994: LVII,1), aceptar el consejo de quien desea el bien para uno (Clemente, 1994: LVIII,2), lleva a no bus- 
car el propio interés sino el del hermano (Clemente, 1994: XLVIII,6) y a vivir los mandamientos, a vivir en el amor un amor que todo lo soporta, que es paciente, que no ocasiona cisma, no se subleva, todo lo hace en armonía (Clemente, 1994: XLIX,5).

Es importante interceder por los que no han encontrado el amor que transforma sus corazones para que hallándolo aniden en su corazón sentimientos de humildad y puedan abandonarse a la voluntad de Dios (Clemente, 1994: LVI, 1). Un auténtico llamado a la conversión que transforma la propia vida y la de la comunidad.

\section{Conclusión}

Clemente escribe su carta para los cristianos de la Iglesia de Corinto a fines del siglo I, pero podemos decir también que escribe a la Iglesia en este siglo ya que afronta temas muy actuales en las comunidades.

Las mismas dificultades que le motivaron a escribir estas líneas las podemos encontrar en cualquier comunidad de personas y en cualquier parte del mundo. Lo importante es reconocer los dones, las cualidades que Dios regaló a cada uno y que no son para reservárselos en el corazón con llave y candado sino que son para el bien de los demás y nada es propio sino que todo es don, todo es gratuidad; de nada tenemos que gloriarnos, enorgullecernos sino sólo de ser cristianos, seguidores de Cristo y sentirnos amados por un Dios familia, un Dios comunidad, un Dios Amor con la certeza de que allí está la fuente del Amor y cuando descubrimos y experimentamos esto en nuestras vidas: no puede haber lugar para la discordia, la disensión, la pelea, la lucha por los primeros puestos, la desobediencia sino simplemente hay una actitud de buscar juntos, como comunidad el Bien, de vivir el proyecto de amor que el Señor dejó y de anunciar el mensaje de Amor a todos los hombres, el anuncio de que Cristo murió y resucitó por amor.

Somos llamados a vivir en la sencillez, en la humildad, donde gratuidad y gratitud se entrelazan, a vivir en la fraternidad, a buscar la paz, a luchar contra los ídolos que amenazan nuestras comunidades, a poner nuestra mirada en Cristo crucificado que desde la cruz nos llama a la libertad, a la entrega, al abandono, a la confianza, a mirar hacia adelante con fe, con esperanza, con caridad, a salir de 'nuestro nido' y a abrirnos a las necesidades de los hermanos, a sembrar la concordia, la fraternidad, a reconciliarnos con nosotros mismos, con los hermanos, con la naturaleza y con Dios para ser felices. Todo esto requiere un continuo y constante camino de conversión, de dejar mirarnos por el Señor, de llenarnos de su misericordia para escuchar su voz que nos llama una vez más a seguirlo en una Iglesia peregrina, en una comunidad convocada para alabar a 
Dios. Está en nosotros responder cada día a esa invitación que nace del encuentro con la Palabra y que debe ser el eje de nuestra vida y de nuestras comunidades que desean permanecer en el Amor, haciendo experiencia del Amor y saliendo de la mediocridad, de la tibieza de la vida cotidiana.

Estamos invitados a contemplar el misterio de la misericordia del Padre, revelada en Jesucristo, porque de la contemplación del mismo nace la paz, la alegría y la serenidad (Francisco, 2015) que para Clemente eran las características que debía tener una comunidad cristiana ya que 'reconocer la misericordia restablece el amor fraterno'. Solo teniendo los ojos fijos en la misericordia del Padre se puede ser signo eficaz de su amor (Francisco, 2015) y de ahí la insistencia de Clemente de pedir el don de la misericordia. Misericordia y fraternidad se entrelazan constantemente.

Ese amor misericordioso de Dios que proviene de sus entrañas es un sentimiento profundo, hecho de ternura y compasión, de perdón y de indulgencia (Francisco, 2015) y Jesús a lo largo de su vida era movido por la misericordia a través de la cual leía el corazón de los interlocutores y respondía con compasión a sus necesidades concretas. Tener una mirada de amor misericordioso, tener entrañas de misericordia para con el hermano es lo que lleva a crecer en una relación de fraternidad, pero es necesario que cada uno primero realice esta experiencia de sentirse perdonado, amado, sanado, liberado para compadecer al hermano que está a su lado. Solo desde la filiación brota la fraternidad. Solo desde la experiencia de ser hijo de un Padre misericordioso brotará una experiencia de fraternidad compasiva, que se inclina ante la necesidad del hermano que está al lado.

Clemente insiste en el perdón para crecer en comunidad. Esto caracteriza a la Iglesia y solo el perdón de las ofensas deviene la expresión del amor misericordioso siendo para todo cristiano un imperativo del que no se puede prescindir (Francisco, 2015). Dejar de lado el enojo, el rencor, la violencia, la venganza son las condiciones necesarias para ser felices. Eso es dejarse conducir por la misericordia.

Experimentar el amor de Dios misericordioso es imprescindible porque la misericordia es la viga maestra que sostiene la Iglesia (Francisco, 2015) ya que esto hace creíble a la Iglesia y Clemente de eso estaba convencido cuando invitaba a los cristianos a esa experiencia que transforma la vida de la Iglesia desde dentro.

Leemos en el documento de Juan Pablo II, Dives in Misericordiae (1979) que la Iglesia vive una vida auténtica cuando profesa y proclama la misericordia y cuando acerca a los hombres a las fuentes de la misericor- 
dia del Salvador, de la que es depositaria y dispensadora (Juan Pablo, 1979).

De esta manera se pone de manifiesto claramente la misión de la Iglesia: anunciar de manera visible, concreta la misericordia de Dios. Donde la Iglesia está presente allí debe manifestarse la misericordia del Padre (Francisco, 2015). Ese es el programa de vida que proponía Clemente en los primeros años de inicio de la Iglesia, desde su magisterio, y esto es lo que hoy nos propone el papa Francisco.

Para vivir este programa de vida es necesario ponerse a la escucha de la Palabra, acoger la Palabra en el corazón, invitar a centrar la vida en la Palabra, una Palabra que escuchada en el silencio transforma el corazón, abre a las necesidades de los demás, no encierra, sino que libera, abre los ojos y los oídos para ver dónde la necesidad es más grande y urgente, dónde el hermano clama, dónde el hermano grita y suplica. Es necesario asumir la misericordia como un estilo de vida y solo desde allí se podría hablar, utilizando las palabras del Papa Francisco, de una 'revolución de la ternura', de una revolución desde la misericordia, desde la compasión. Solo así podemos hablar de fraternidad.

Junto al silencio y la escucha es necesario superar la envidia, los celos, los juicios, las críticas demoledoras que no ayudan a crecer en fraternidad y saber descubrir los dones, valores, cualidades, lo bueno que el Señor colocó en el corazón del hermano con la certeza de que El da a cada uno dones y esos dones son para colocarlos al servicio de los demás, en complementariedad, siendo corresponsables del crecimiento de quien camina junto a nosotros, en un enriquecimiento recíproco y con la certeza de que alimentan la vida comunitaria. Y junto a estas actitudes es necesario el perdón: dar y recibir perdón; tener una actitud de generosidad porque como cada uno es perdonado por el Padre, así lo pedimos en la oración que nos une como comunidad, 'perdona nuestras ofensas' y continuamos 'como nosotros perdonamos a los que nos ofenden'. Hacer experiencia del perdón misericordioso para derramar misericordia y ser capaces de dar el primer paso, de acercarnos con entrañas de misericordia a aquel que ofendimos o a aquel que tiene algo contra nosotros.

Sentir la cercanía, la ayuda de Dios que sale a nuestro encuentro tiene que despertar en cada uno, en cada cristiano, en cada cristiana la compasión, el salir al encuentro, el 'salir a las periferias geográficas y existenciales', el curar las heridas de tantos hermanos que sufren. No caer en la indiferencia del hermano que se siente despreciado, 'ninguneado', al cual no se le reconoce su dignidad de persona, no pasar de largo, como el sacerdote y el publicano de la parábola, no mirar hacia el otro lado ante los que sufren física, moral y espiritualmente. No ceder al individualismo, a la comodidad, al 'no meterme', 'no jugarme', que caracteriza la realidad 
presente: ese es parte del programa de vida para crecer en una Iglesia fraterna y misericordiosa. Tender la mano, estrecharla al hermano que sufre para que sienta en ese apretón de mano el amor de un Dios que es Padre lleno de misericordia, que ama a sus hijos, que olvida sus errores, sus pecados y que continuamente invita a levantarse y caminar.

Descubrir en cada hermano el rostro de Cristo que sufre, que clama, que está herido, que necesita ser sanado, liberado de las esclavitudes que la misma sociedad de hoy genera, de las cegueras que le impiden ver las maravillas que Dios obra en su corazón, la luz que hay en su propio interior porque se ha encerrado en sí mismo, en sus dolores y sufrimientos; a devolverle la verdadera dignidad de hijo de Dios y hermano, a ayudar a redescubrir el sentido de la propia vida, su misión, su para qué Dios lo colocó en este mundo, su proyecto de vida.

La Iglesia está llamada a ser misionera, anunciadora de la buena noticia de la misericordia y de la compasión, del perdón y del amor con la certeza de que ese es el verdadero fundamento de la Iglesia fraterna. Anuncio que invita a la conversión, a cambiar el corazón, a abrirse a la justicia, a la verdad, a la sinceridad.

María, la mujer que llevó en su seno al Hijo del Padre Eterno, que visitó a Isabel y cantó el Magnificat, proclamando las maravillas que el Señor hizo en Ella, nos acompañe para que como Iglesia cantemos las maravillas del amor de Dios que obra en cada uno e invita a crecer en el amor y la fraternidad.

\section{REFERENCIAS}

-Ayán, J. (1994). Introducción a la carta a los Corintios. Madrid: Ciudad Nueva. -Clemente de Roma (1994). Carta a los Corintios. Madrid: Ciudad Nueva.

-Contreras, E. \& Peña, R. (1990). Introducción al estudio de los Padres. Periodo preniceno. Azul: Monasterio Trapense.

-Eusebio de Cesarea (2000). Historia Eclesiástica. Madrid: Biblioteca de Autores cristianos.

-Fernández, G. (2002). Algunas cuestiones en torno a la historia antigua de la Iglesia romana. Anuario de Historia de la Iglesia, 11, 281-289.

-Francisco (2015). Misericordia V ultus. Buenos Aires: Paulinas.

-Ireneo (2000). Adversus Haereses. Madrid: Biblioteca de Autores cristianos. -Juan Pablo II (1979). Dives in Misericordia. Buenos Aires: San Pablo.

-Loarte, J. (1998). El tesoro de los Padres. Selección de textos de los Santos Padres para el cristiano del tercer milenio. Madrid: Rialp.

-Quasten, J. (1968). Patrología I. Hasta el Concilio de Nicea. Madrid: Biblioteca de Autores cristianos. 
-Ruíz Bueno, D. (2002). Padres apostólicos y apologistas griegos del siglo II. Madrid: Biblioteca de Autores cristianos.

Sumario: Introducción; 1. Los orígenes de Clemente Romano; 2. La carta a la Iglesia de Corinto; 3. La Iglesia en la carta a los Corintios; 3.1 Identidad y misión de la Iglesia de Corinto; 3.2 Dificultades en la iglesia de Corinto; 4. Un programa de vida; Conclusión; Referencias. 